\title{
Independent Resistant Reactions Expressed in Root and Tuber of Potato Breeding Lines with Introgressed Resistance to Meloidogyne chitwoodi
}

\author{
C. R. Brown, H. Mojtahedi, L.-H. Zhang, and E. Riga
}

First author: Research Geneticist and second author: Research Affiliate, United States Department of Agriculture-Agricultural Research Service, Prosser, WA 99350; and third author: Research Associate and fourth author: Assistant Professor and Extension Nematologist, Washington State University, Irrigated Agriculture Research and Extension Center, Prosser. Accepted for publication 21 April 2009.

\begin{abstract}
Brown, C. R., Mojtahedi, H., Zhang, L.-H., and Riga, E. 2009. Independent resistant reactions expressed in root and tuber of potato breeding lines with introgressed resistance to Meloidogyne chitwoodi. Phytopathology 99:1085-1089.

Resistance to Meloidogyne chitwoodi was introgressed from Solanum bulbocastanum into the cultivated gene pool of potato. A single dominant gene is responsible for resistance to race 1 reproduction on the root system. An additional form of resistance was discovered in certain advanced backcross clones. A $\mathrm{BC}_{5}$ clone, PA99N82-4, resisted invasion of tubers by available nematode juveniles whether supplied by weeds or challenged by several root resistance-breaking pathotypes. This tuber resistance is inherited as a single dominant gene and is linked to $R_{M c l(b l b)}$. Because this gene has been mapped to chromosome 11, tuber

ble tuber and susceptible root/resistant tubers, were found while other progeny were doubly resistant (like PA99N82-4) or doubly susceptible. Therefore, the existence of two linked genetic factors controlling independently expressed traits is confirmed. The combination of the two phenotypes is likely to be a sufficient level of resistance to avoid tuber damage from circumstances that provide exogenous juveniles proximal to the tubers in the soil. These factors are weed hosts of $M$. chitwoodi host races and pathotypes of $M$. chitwoodi that overcome $R_{M c l(b l b)}$. Under field conditions, where a resistance-breaking pathotype of $M$. chitwoodi was present, tuber-resistant PA99N82-4 breeding line produced tubers which were commercially acceptable and not culled. A related breeding line, root resistant but tuber susceptible, and Russet Burbank were severely tuber damaged and commercially unacceptable.
\end{abstract} resistance genetic factors are inferred to be on the same chromosome in coupling phase. Among 153 progeny derived from crosses with PA99N82-4, 42 recombinants, comprising both resistant root/suscepti-
Additional keywords: Columbia root-knot nematode.
Meloidogyne chitwoodi Golden et al., causal agent of Columbia root-knot nematode (CRKN), is a serious pest of potato in the Pacific Northwest (PNW) of the United States (21). The soilinhabiting second-stage juveniles (J2) of CRKN increase on emerging roots of potato and attack tubers at 900 degree-days at a base temperature of $6^{\circ} \mathrm{C}\left(\mathrm{DD}_{\left(6^{\circ} \mathrm{C}\right)}\right)(17)$, causing blemishes that are, in fact, female infestation sites that render the crop unmarketable. Presently, growers have limited options to control this pest. Crop rotation to control CRKN has several limitations in the PNW. First, CRKN has a wide host range and, due to a very low damage threshold, even the most successful rotation will leave a residual population that, by the end of a long warm growing season, will result in unacceptable economic losses. Furthermore, the occurrence of several host races and pathotypes of CRKN makes it difficult to find nonhosts that would remove the threat of damage. At present, soil fumigation with 1,3dichloropropene, metam sodium, or both is the only affordable option available for growers. Although fumigation is an effective measure, it is costly and may have a negative environmental impact.

Corresponding author: C. R. Brown; E-mail address: chuck.brown@ars.usda.gov

doi:10.1094/PHYTO-99-9-1085

This article is in the public domain and not copyrightable. It may be freely reprinted with customary crediting of the source. The American Phytopathological Society, 2009.
Ideally, a resistant potato cultivar with commercially acceptable traits will address all the drawbacks of control measures described above. We have initiated a breeding program at the United States Department of Agriculture-Agricultural Research Service unit in Prosser and successfully incorporated resistance gene $R_{M c l(b l b)}$, derived from Solanum bulbocastanum Dunn. $(3,5)$, into the cultivated potato gene pool. The resistance gene prevents host race 1 of CRKN (CRKN-1) from reproducing on the potato roots and, therefore, tubers escape nematode damage. CRKN-1 of $\mathrm{CRKN}$ is the predominant race in potato-growing regions of PNW (H. Mojtahedi, unpublished).

In a field infested with CRKN-1, we observed that tubers of some resistant breeding lines were damaged by nematodes. The plot sites were weedy by the end of the growing season, with hairy nightshade (HN) (S. physaliofolium Rusby, previously $S$. sarrachoides Sendtner) predominating in the plots. HN is a host of CRKN (1), and nematodes increased on the roots of the weed host before attacking the tubers. This observation suggested that a breeding line may resist nematode reproduction on roots but still be vulnerable to tuber infection if juveniles are abundant in the soil around the tubers. It was noteworthy that one breeding line in particular, PA99N82-4, remained damage free in the weedy plot, supporting the notion that root and tuber resistance might be independently inherited traits. The purpose of this study was to answer two questions: (i) is the resistance to nematode reproduction on the roots of breeding lines independent from resistance to infection in its tubers and (ii) is tuber resistance in PA99N82-4, observed in field plots, limited to host race 1 for which it was 
bred or will it be expressed against other host races and pathotypes of CRKN?

\section{MATERIALS AND METHODS}

Nematode inocula. The impact of two host races and two pathotypes of CRKN on selected breeding lines and Russet Burbank was evaluated in these studies. CRKN-1 was originally isolated from a potato field in Quincy, WA and labeled WAMC1 in our collection (13). CRKN-1 parasitizes 'Chantenay' carrot, but does not reproduce on 'Thor' alfalfa. In contrast, host race 2 (CRKN-2), parasitizes alfalfa but does not reproduce on carrot (11). This population was also isolated from a potato field in Washington (22) and labeled WAMC27 in the nematode collection at Prosser (11). Both CRKN-1 and CRKN-2 will not reproduce on clone 22 of $S$. bulbocastanum (SB22); however, both PA99N82-1 and PA95B4-67 have root resistance to race 1, pathotype 1 of $\mathrm{CRKN}-1\left(\mathrm{CRKN}-1_{(\mathrm{Pl})}\right)$. which has host preferences similar to CRKN-1 except that it breaks the resistance gene $R_{M c l(b l b)}$ and multiplies on SB22. This population of CRKN was newly reported from an experimental field in Washington where our breeding lines have been cultivated for the past 15 years (9) and is labeled WAMCRoza. Pathotype1 of CRKN-2 (CRKN2 $\left.2_{(\mathrm{P} 1)}\right)$, which was isolated from a potato field in Tulelake, CA (12), is similar in host preference to CRKN-2, except that it can break the resistance gene $R_{M c l(b l b)}$ and parasitizes SB22. This population is labeled CAMC2 in the Prosser collection. Designating two pathotypes, one each of host races 1 and 2, is in accordance with Roberts (18) and Mojtahedi et al. (12) treatments of conceptual aspects of variability in root-knot nematodes. All CRKN host races and pathotypes reproduce on 'Rutger' tomato (Tables 1 and 2 ). Eggs of CRKN that had been maintained on tomato were extracted from roots using the methods of Jenkins (8) and Hussey and Barker (7). Five thousand eggs in a volume of $5 \mathrm{ml}$ were added around each potted plant at inoculation.

Plant materials. The derivation of CRKN-1-resistant clones used in this study was presented by Brown et al. (3). Briefly, they resulted from an introgression of the genetic factors responsible for resistance from diploid S. bulbocastanum (PI 275187, NRSP6, Sturgeon Bay, WI) into backcrosses 4 and 5 for tetraploid PA95B4-67 and PA99N82-4, respectively. Backcross introgressants displayed root resistance to CRKN-1. To increase seed tubers of resistant lines, the nuclear seed were grown at the Central Oregon Experiment Station at Powell Butte, OR. Tetraploid
Russet Burbank, a cultivar susceptible to all races and pathotypes of CRKN, was grown from nematode-free certified seed tubers. Progeny of a cross of tetraploids, PA99N82-4 (root and tuber resistant) $\times$ Norkotah Russet (doubly susceptible), were tested for expression of root and tuber resistance. The extracted seed was treated with gibberellic acid at $1,500 \mu \mathrm{g} \operatorname{liter}^{-1}$ (Sigma Aldrich, St. Louis) solution by soaking for $24 \mathrm{~h}$, rinsing in tap water, drying, and sowing. Seedlings were grown in 8 -cm-diameter plastic pots and the multiple tubers were harvested from each pot, identified as a clone, and maintained clonally with that identity.

Progeny were evaluated for resistance in the roots and tuber. HN seed was extracted from locally collected berries and treated with gibberellic acid at $1,500 \mu \mathrm{g} \operatorname{liter}^{-1}$ for $48 \mathrm{~h}$ prior to germinating at $29^{\circ} \mathrm{C}$ in the dark. Seedlings in the cotyledon stage were transplanted into small pots containing soil (described later).

The control plants included Rutgers tomato, Thor alfalfa, Chantenay carrot, and 'California Wonder' pepper, and were grown from commercial seed. SB22 plants were generated from tissue culture plantlets. Inclusion of control plants was to ascertain the viability of CRKN egg inocula and purity of different host races and pathotypes used in these studies (Table 1). Pepper was included to show the freedom of inocula from $M$. hapla Chitwood, another root-knot nematode species common in the PNW. M. hapla reproduces on pepper, whereas CRKN does not.

Greenhouse tests. Impact of exogenous inoculum. Adopting the technique of Boydston et al. (1), we used nightshade seedlings planted concomitantly with potato to provide exogenous nematodes around the roots of resistant potato breeding lines that are nonhosts for CRKN-1. Four-week-old potato seedlings of Russet Burbank and two breeding lines resistant to CRKN-1, PA95B4-67 and PA99N82-4, were transplanted into 4-liter plastic pots half filled to capacity with methyl-bromide-fumigated $\left(0.3 \mathrm{~kg} / \mathrm{m}^{3}\right)$ loamy sand soil $(84 \%$ sand, $10 \%$ silt, $6 \%$ clay $)$. A single 1-month-old HN seedling was also transplanted into each pot. CRKN-1 was added around the roots of potato and nightshade and covered with soil. As plants grew, fumigated soil was added to the pots to ensure that newly formed tubers remained under the soil surface and exposed to nematodes. Five replicates of each treatment were planted.

For this experiment and the one that follows, control plants were planted in $25-\mathrm{cm}$-diameter clay pots and all pots were maintained on a greenhouse bench at 21 to $27^{\circ} \mathrm{C}$ ambient temperature for the duration of the studies.

TABLE 1. Host race and pathotype designation of Meloidogyne chitwoodi in the Pacific Northwest of the United States

\begin{tabular}{|c|c|c|c|c|c|}
\hline \multirow[b]{2}{*}{ Populations of $M$. chitwoodi ${ }^{\mathrm{z}}$} & \multicolumn{5}{|c|}{ Host differentials } \\
\hline & Tomato & Carrot & Alfalfa & SB22 & Pepper \\
\hline CRKN-1 (host race 1) & + & + & - & - & - \\
\hline $\mathrm{CRKN}-1_{(\mathrm{P} 1)}$ (pathotype 1 of race 1$)$ & + & + & - & + & - \\
\hline CRKN-2 (host race 2) & + & - & + & - & - \\
\hline $\mathrm{CRKN}-2_{(\mathrm{P} 1)}$ (pathotype 1 of race 2$)$ & + & - & + & + & - \\
\hline
\end{tabular}

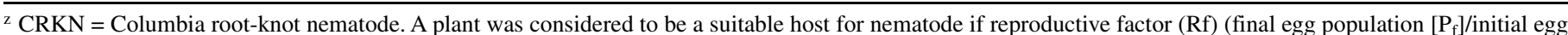
population $\left[\mathrm{P}_{\mathrm{i}}\right]$ ) value $\geq 1$, a poor host if $\mathrm{Rf} \leq 1$, and a nonhost if $\mathrm{Rf}<0.1$.

TABLE 2. Reproductive factor (Rf) of Meloidogyne chitwoodi host races and pathotypes on host differentials 55 days after inoculation with 5,000 eggs ${ }^{\mathrm{y}}$

\begin{tabular}{|c|c|c|c|c|c|}
\hline \multirow[b]{2}{*}{ Populations of $M$. chitwoodi $^{\mathrm{z}}$} & \multicolumn{5}{|c|}{ Host differentials } \\
\hline & Tomato 'Rutger' & Carrot 'Chantenay' & Alfalfa 'Thor' & Solanum bulbocastanum clone 22 & Pepper 'CA Wonder' \\
\hline CRKN-1 (host race 1) & $5.6 \mathrm{c}$ & $1.7 \mathrm{a}$ & $0 \mathrm{~b}$ & $0.04 \mathrm{c}$ & $0 \mathrm{a}$ \\
\hline CRKN-1 $1_{(\mathrm{P} 1)}($ pathotype 1 of race 1$)$ & $53.3 \mathrm{a}$ & $3.9 \mathrm{a}$ & $0.04 \mathrm{~b}$ & $17.2 \mathrm{a}$ & $0 \mathrm{a}$ \\
\hline CRKN-2 (host race 2) & $28.6 \mathrm{~b}$ & $0.004 \mathrm{~b}$ & $19.8 \mathrm{a}$ & $0.01 \mathrm{c}$ & $0 \mathrm{a}$ \\
\hline $\mathrm{CRKN}-2_{(\mathrm{P} 1)}($ pathotype 1 of race 2$)$ & $42.7 \mathrm{a}$ & $0.01 \mathrm{~b}$ & $12.4 \mathrm{a}$ & $9.0 \mathrm{~b}$ & $0 \mathrm{a}$ \\
\hline
\end{tabular}


compiled from three experiments and each mean is an average of three observations per run. A plant was considered to be a suitable host for nematode if Rf (final egg population $\left[\mathrm{P}_{\mathrm{f}}\right] /$ initial egg population $\left[\mathrm{P}_{\mathrm{i}}\right]$ ) value $\geq 1$, a poor host if $\mathrm{Rf} \leq 1$, and a nonhost if $\mathrm{Rf}<0.1$.

z $\mathrm{CRKN}=$ Columbia root-knot nematode. 
Impact of four different nematode populations. The reproduction and tuber damage of two host races, CRKN-1, and CRKN-2, and two known pathotypes, CRKN-1 $1_{(\mathrm{P} 1)}$ and CRKN$2_{(\mathrm{P} 1)}$, of $M$. chitwoodi on Russet Burbank, PA95B4-67, and PA99N82-4 was tested in the absence of nightshade. Planting, inoculation, and maintenance of pots were similar to the previous experiment. At the end of each experiment, the number of CRKN eggs produced on roots of test plants was estimated by determining the number of eggs in 1-ml aliquots from 50-ml extracts, and the reproductive factor (Rf) calculated according to the equation $R f=P_{f} / P_{f}$, where $P_{f}$ represents the final egg count and $P_{i}$ the initial inoculum (i.e., 5,000 eggs) (16). Tuber infection was assessed by rating infection sites at 3 months after transplanting by counting the browned infection sites on the flesh of peeled tubers (for rating, see Tables 3 to 5) (14). Incidence of infection was calculated as the ratio of the number of tubers with any nematode infection site in the flesh/the total scored $\times 100$. A tuber was not classed as a cull unless it had six or more female infestation sites. Treatment means for $\mathrm{Rf}$ were separated by Duncan's multiple range test and treatment means for tuber damage by the Mann and Whitney nonparametric paired comparison test. Analysis was based on the compilation of two experiments or 10 replications in total.

Field tests. Field trials were conducted on the Roza Unit of the Washington State University Irrigated Agriculture $\mathrm{Re}$ search and Extension Center for 3 years, comparing Russet Burbank, PA95B4-67, and PA99N82-4. The Roza Unit is the site where $\mathrm{CRKN} 1_{(\mathrm{Pl})}$ was originally collected and identified (14). The purpose of these trials was to determine the durability of resistance in PA99N82-4 tubers under field conditions where $\mathrm{CRKN} 1_{(\mathrm{P} 1)}$ was also present. The experiments were planted in either of two side-by-side fields which are planted with test plots every other year. In the nonpotato years, field corn was grown.

Seed for these trials was obtained from the Central Oregon Experiment Station facility in Powell Butte, OR, to provide seed equivalent to certified virus-indexed seed for planting.

Cut seed pieces, 43 to $85 \mathrm{~g}$ in size, were planted in 10 -seedpiece plots in a randomized complete block design with four replications. Plants were $23 \mathrm{~cm}$ apart in rows, with spacing between rows of $86 \mathrm{~cm}$. The site was fertilized in April with $\mathrm{N} / \mathrm{P} / \mathrm{K}$ at 122/224/336 kg/ha (Simplot, WA) broadcast over the surface. The site has a silt soil and was irrigated with a solid-set sprinkler system. Rimsulfuron (DuPont, Wilmington, DE) was applied as a post-planting herbicide and late blight (Phytophthora infestans (Mont.) de Bary) and Colorado potato beetle (Leptinotarsa decemlineata (Say)) were chemically controlled by chlorothalonil and imidicloprid, respectively.

The harvested tubers were graded initially to remove rotten and misshapen tubers; then, 20 of the sound tubers per replicated plot were rated for nematode infection (Tables 3 to 5).
Inheritance of root and tuber resistances. In all, 153 progeny of PA99N82-4 were tested by inoculating them in two ways: (i) three potato replicates were inoculated with $\mathrm{CRKN}-1$ as described above and (ii) three additional replicates were combined with HN and inoculated with CRKN-1 in a similar fashion. Progeny grown without HN served as a measure of root resistance. Segregants were classified as root resistant if $\mathrm{Rf}<0.1$ and susceptible if $\mathrm{Rf}>$ 1.0. In pots where potato and HN shared the soil environment, nematodes reproducing on the $\mathrm{HN}$ were available to $R_{M c l(b l b)}$ genotypes to assess tuber resistance, thus revealing the recombinant phenotype root resistant/tuber susceptible. The roots were assessed at 55 days after inoculation by egg extraction and calculation of Rf. The Rf of the potato roots was based on egg counts extracted from root systems grown without HN. Tubers produced in co-culture with $\mathrm{HN}$ were stored at $20^{\circ} \mathrm{C}$ for 2 months

TABLE 4. Reproductive factor of Meloidogyne chitwoodi host races and pathotypes on Russet Burbank, PA99N82-4, and PA95B4-67 and damage caused on tubers 3 mo after inoculating with 5,000 eggs in pots

\begin{tabular}{lcccc}
\hline & \multicolumn{4}{c}{ M. chitwoodi host races and pathotypes ${ }^{\mathrm{v}}$} \\
\cline { 2 - 5 } Test plants & CRKN-1 & CRKN-1 $(\mathrm{P} 1)$ & CRKN-2 & CRKN-2 $_{(\mathrm{P} 1)}$ \\
\hline Rf $^{\mathrm{w}}$ & $1.8 \mathrm{a}$ & $7.0 \mathrm{~b}$ & $1.0 \mathrm{~b}$ & $5.6 \mathrm{~b}$ \\
Russet Burbank & $0.001 \mathrm{~b}$ & $5.3 \mathrm{~b}$ & $1.1 \mathrm{~b}$ & $6.2 \mathrm{~b}$ \\
PA99N82-4 & $0.03 \mathrm{~b}$ & $13.0 \mathrm{a}$ & $23.3 \mathrm{a}$ & $32.2 \mathrm{a}$ \\
PA95B4-67 & & & & \\
Disease incidence (\%) & & & & \\
Russet Burbank & $50 \mathrm{a}$ & $85 \mathrm{a}$ & $53 \mathrm{~b}$ & $89 \mathrm{a}$ \\
PA99N82-4 & $0 \mathrm{~b}$ & $22 \mathrm{~b}$ & $21 \mathrm{c}$ & $3 \mathrm{~b}$ \\
PA95B4-67 & $7 \mathrm{~b}$ & $30 \mathrm{~b}$ & $75 \mathrm{a}$ & $85 \mathrm{a}$ \\
Infection index & & & & \\
Russet Burbank & $1.6 \mathrm{a}$ & $3.6 \mathrm{a}$ & $1.2 \mathrm{~b}$ & $5.4 \mathrm{a}$ \\
PA99N82-4 & $0.0 \mathrm{~b}$ & $0.4 \mathrm{c}$ & $0.2 \mathrm{c}$ & $0.03 \mathrm{~b}$ \\
PA95B4-67 & $0.07 \mathrm{~b}$ & $1.5 \mathrm{~b}$ & $4.0 \mathrm{a}$ & $4.3 \mathrm{a}$ \\
Tubers culled $(\%)^{\mathrm{z}}$ & & & & \\
Russet Burbank & $35 \mathrm{a}$ & $78 \mathrm{a}$ & $33 \mathrm{~b}$ & $89 \mathrm{a}$ \\
PA99N82-4 & $0 \mathrm{~b}$ & $4 \mathrm{c}$ & $0 \mathrm{c}$ & $0 \mathrm{~b}$ \\
PA95B4-67 & $0 \mathrm{~b}$ & $23 \mathrm{~b}$ & $75 \mathrm{a}$ & $85 \mathrm{a}$ \\
\hline
\end{tabular}

${ }^{v}$ Columbia root-knot nematode $(\mathrm{CRKN})-1$ and $2=$ host race 1 and 2 , respectively; P1 indicates pathotype of each race. The figures in each column are averages of 7 replications for $\mathrm{Rf}$ values or 10 replications for nematode damage assessments, which were based on two experiments, each with five replications. Rf means not followed by the same letter differ at $P<0.05$ according to Duncan's multiple range tests, and those of tuber damage by the Mann \& Whitney nonparametric paired comparison test.

${ }^{\mathrm{w}} \mathrm{Rf}$ (reproductive factor) $=$ number of eggs recovered from roots 3 months after inoculation/initial inoculum of 5,000 eggs.

${ }^{x}$ Disease incidence was based on presence or absence of browned infection site caused by nematodes, regardless of intensity of infection.

y Infection index was based on presence of browned infection sites caused by nematodes; $0=$ no browned infection site, $1=1$ to $3,2=4$ to $6,3=6$ to 25 , $4=25$ to $50,5=50$ to 100 , and $6>100$ browned infection sites on tuber surface.

${ }^{\mathrm{z}}$ A tuber was considered culled if it had $\geq 6$ browned infection sites.


lines grown with and without hairy nightshade $(\mathrm{HN})$ in pots in the greenhouse for 3 months after inoculating with 5,000 eggs ${ }^{\mathrm{w}}$

\begin{tabular}{|c|c|c|c|c|c|c|}
\hline \multirow[b]{2}{*}{ Treatments $^{\mathrm{x}}$} & \multicolumn{3}{|c|}{$\mathrm{Rf}^{\mathrm{y}}$} & \multicolumn{3}{|c|}{ Tuber infection index ${ }^{\mathrm{z}}$} \\
\hline & Russet Burbank & PA95B4-67 & PA99N82-4 & Russet Burbank & PA95B4 67 & PA99N82-4 \\
\hline No nematode (control) & - & - & - & 0 & 0 & 0 \\
\hline Nematodes & $39.2 \mathrm{a}$ & $0.001 \mathrm{~b}$ & $0 \mathrm{~b}$ & $3.6 \mathrm{a}$ & $0.03 \mathrm{~b}$ & $0.0 \mathrm{~b}$ \\
\hline Nematodes and HN seedlings & $43.6 \mathrm{a}$ & $21.8 \mathrm{~b}$ & $1.4 \mathrm{c}$ & $3.3 \mathrm{a}$ & $2.0 \mathrm{a}$ & $0.01 \mathrm{~b}$ \\
\hline
\end{tabular}

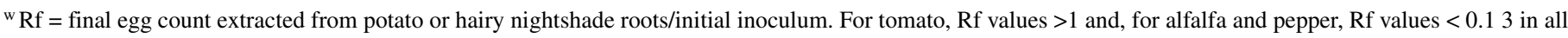
experiments months after transplanting.

$x$ Nematodes or nematodes and HN seedlings added at transplanting.

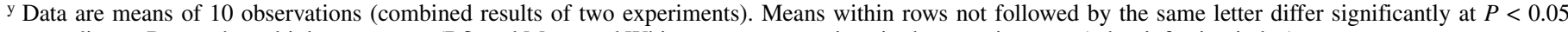
according to Duncan's multiple range tests (Rf) and Mann and Whitney nonparametric paired comparison test (tuber infection index).

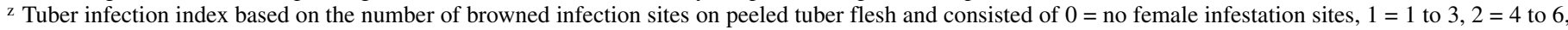
$3=6$ to $25,4=25$ to $50,5=50$ to 100 , and $6>100$ female infestation sites. For each observation, 1 to 10 tubers were evaluated at 3 months after transplanting. Number of trials $=2$. 
and then peeled and scored for tuber damage as described above. Tubers were classified as resistant to tuber damage if they had fewer than six female infestation sites. The Kosambi function was used to calculate distance $(d)$ as $d=(-1 / 2) \ln (1-2 r)$, where $r$ is the frequency of recombinants (6).

\section{RESULTS AND DISCUSSION}

Greenhouse tests. All CRKN host races and pathotypes were viable (reproduced on tomato) and pure (reproduced only on their respective differential hosts) (Table 2). Thus, they conformed to their stated identity (Table 1) as previously reported $(9,11)$. Although there were significant differences between $\mathrm{Rf}$ values of the nematode populations on tomato, we did not consider them to have a significant effect on the reported results, because tomato was a suitable host for each isolate.

Impact of exogenous inoculum. $\mathrm{CRKN}-1$ successfully parasitized Russet Burbank roots and caused typical external and internal symptoms on tubers $(1,2)$.

CRKN-1 failed to reproduce on the roots of PA99N82-4 and PA95B4-67 and did not cause any significant damage to tubers of these two breeding lines when grown without HN (Table 3); thus, they escaped tuber damage. However, when HN was grown in pots with the resistant potato breeding lines, the number of eggs recovered from combined roots of the two species was increased significantly (Table 3 ). Nematodes provided by $\mathrm{HN}$ impacted only the tubers of PA95B4-67 and not those of PA99N82-4. Boydston et al. (1) showed that, if CRKN-1-infected HN plants were introduced into pots 2 months after transplanting, the nematodes were able to cause damage on Russet Burbank and PA95B4-67 tubers but not on those of PA99N82-4. Their observations confirm that PA95B4-67 tubers are susceptible to juvenile invasion. It is already known that Russet Burbank tubers remain vulnerable to juvenile invasion long after tubers are initiated (18). These results clearly demonstrate that root and tuber resistance to infection by

TABLE 5. Root-knot nematode disease attributes: incidence (\%), infection index, and percent tubers culled during 3 years of field trials in an experimental field proved to be infested with Columbia root-knot nematode (CRKN) pathotype of host race $1^{\mathrm{w}}$

\begin{tabular}{lccc}
\hline & \multicolumn{3}{c}{ Nematode disease attributes } \\
\cline { 2 - 4 } & Incidence $(\%)^{\mathrm{x}}$ & Infection index $^{\mathrm{y}}$ & ${\text { Culled }(\%)^{\mathrm{z}}}$ \\
\hline 2003 & $100 \pm 0$ & $5.0 \pm 0.0$ & $100 \pm 0$ \\
Russet Burbank & $97 \pm 2$ & $2.7 \pm 0.6$ & $98 \pm 5$ \\
PA95B467 & $23 \pm 6$ & $0.25 \pm 0.05$ & $0 \pm 0$ \\
PA99N82-4 & $100 \pm 0$ & $6.0 \pm 0.0$ & $100 \pm 0$ \\
2005 & $97 \pm 3$ & $3.7 \pm 0.4$ & $75 \pm 10$ \\
Russet Burbank & $36 \pm 10$ & $0.7 \pm 0.3$ & $4 \pm 3$ \\
PA95B467 & $100 \pm 0$ & $5.3 \pm 0.5$ & $90 \pm 7$ \\
PA99N82-4 & $13 \pm 9$ & $0.3 \pm 0.2$ & $5 \pm 3$ \\
2006-1 & $3 \pm 3$ & $0.03 \pm 0.03$ & $0 \pm 0$ \\
Russet Burbank & $88 \pm 13$ & $4.4 \pm 1.2$ & $73 \pm 24$ \\
PA95B467 & $\mathrm{ND}$ & $\mathrm{ND}$ & $\mathrm{ND}$ \\
PA99N82-4 & $28 \pm 9$ & $0.3 \pm 0.1$ & $0 \pm 0$ \\
2006-2 & & & \\
Russet Burbank & & & \\
PA95B467 & & & \\
PA99N82-4 & & & \\
\hline
\end{tabular}

${ }^{w}$ Trials every year were planted in a complete randomized block design with four replications. Twenty tubers per replicate were evaluated for CRKN disease attributes.

x Disease incidence was based on presence or absence of browned infection sites caused by nematode (regardless of intensity of infection).

y Infection index was based on female infestation sites caused by the establishment of nematodes, where $0=$ no female infestation site, $1=1$ to 3 , $2=4$ to $6,3=6$ to $25,4=25$ to $50,5=50$ to 100 , and $6>100$ female infestation sites on peeled tuber surface.

${ }^{\mathrm{z}}$ A tuber was considered culled if it had $\geq 6$ browned infection sites. Several commercial processors practice less strict quality control measures. ND $=$ no data.
CRKN-1 are independent events, and CRKN-1 may persist in the rhizophere of a breeding line such as PA99N82-4 without infecting its tubers. In contrast, for breeding lines such as PA95B467, if a nearby source of inoculum exists, the tubers will be damaged. Santo et al. (20) reported a similar observation on another breeding line originated from the Prosser breeding program.

Impact of four different nematode populations. The data from two experiments were combined because there was no interaction between genotype and nematode races and pathotypes. Russet Burbank, a potato cultivar susceptible to M. chitwoodi, was damaged by all CRKN races and pathotypes, and the intensity of tuber damage was a function of nematode density at harvest (Table 4). In contrast, PA99N82-4 and PA95B4-67 roots were not colonized by $\mathrm{CRKN}-1$, and tubers were not damaged significantly. The disease incidence of $7 \pm 7$ for PA95B4-67 exposed to CRKN-1 was not statistically $(P>0.05)$ different from that of PA99N82-4 $(0 \pm 0)$. However, race 2 and the two pathotypes of CRKN increased on the roots of PA95B4-67 and damaged the tubers. As with Russet Burbank, the intensity of damage depended on the density of the population at harvest. Similarly, all CRKN populations, other than CRKN-1, reproduced on PA99N82-4, but none caused significant damage on its tubers. In fact, the incidence of $4 \pm 4 \%$ of tubers of PA99N82-4 that were classified as culls by virtue of $\mathrm{CRKN}-1_{(\mathrm{P} 1)}$ damage was not significantly different from those exposed to CRKN-1, with $0 \pm 0$ incidence (Table 4). The similarity of root system host response of two breeding lines tested, that supported nematode reproduction of race 2 and two pathotypes of CRKN, and the dissimilarity of their tuber reaction toward those nematodes indicate distinct phenotypes (10). The breakdown of PA95B4-67 in multiyear tests has been attributed to nematodes propagated on weed root systems (1) and the appearance of a resistance-breaking pathotype, $\mathrm{CRKN}-1_{(\mathrm{P} 1)}(14)$. The durable resistance of PA99N82-4 is ascribed in this article to a previously undescribed tuber resistance.

Field test. Although the field population of $\mathrm{CRKN}-1_{(\mathrm{P} 1)}$ was not monitored on a regular basis, presence of Russet Burbank ensured that escape from damage due to patchy distribution would be detected. In 2003 and 2005, although Russet Burbank and PA95B4-67 tubers were severely damaged (i.e., 65 to $100 \%$ of tubers damaged) (Table 5), none of PA99N82-4 tubers were rated as a culled tuber during 2003 to 2006 trials (less than six browned infection site per tuber) (Table 5). In 2006 at site 1, the percentage of culled tubers of PA95B4-67 was significantly less than Russet Burbank (10 versus 90\%); nevertheless, it was high enough to be on the verge of rejection by commercial processors. No explanation exists for this aberrant result.

Inheritance. Brown et al. (4,5) and Zhang et al. (23) showed that the root resistance gene, $R_{M c l(b l b)}$, is located on chromosome

TABLE 6. Co-segregation of root and tuber resistance in progeny of cross of PA99N82-4 $\times$ Norkotah Russet ${ }^{\mathrm{Z}}$

\begin{tabular}{lccc}
\hline Resistance/susceptibility & $\begin{array}{c}\text { Root } \\
\text { resistant }\end{array}$ & $\begin{array}{c}\text { Root } \\
\text { susceptible }\end{array}$ & $\begin{array}{c}\text { Marginal } \\
\text { numbers }\end{array}$ \\
\hline Tuber resistant & 56 & 22 & 78 \\
Tuber susceptible & 20 & 55 & 75 \\
Marginal numbers & 76 & 77 & 153 \\
\hline
\end{tabular}

${ }^{\mathrm{z}}$ Progeny were inoculated with Columbia root-knot nematode (Meloidogyne chitwoodi, race 1) and the root systems evaluated for reproductive factor value (final population/initial population) to determine host status. Three replicate pots were planted with hairy nightshade (Solanum physaliofolium), a good host for race 1 and a source of exogenous tuber inoculum in cases where the root system was resistant. The expectation of 1:1 segregation for resistant versus susceptible for root and tuber resistance considered separately was not rejected by $\chi^{2}$ analysis $\left(\chi^{2}=0.06\right.$ for tuber resistance and $\chi^{2}=$ 0.006 for root resistance, not significant). Lack of independent association of traits indicated by $\chi^{2}=31.1$, which is highly significant $(P<0.001)$. 
11. The segregation of progeny of PA99N82-4 $\times$ Norkotah Russet revealed that resistance in the roots and tubers presented four distinct phenotypes (i.e., resistant or susceptible reactions on roots and tubers with no intermediate categories). The four phenotypes were not associated independently (Table 6). There was a deficit of resistant root/susceptible tuber and susceptible root/resistant tuber recombinants $\left(\chi^{2}=31.1, P<0.001\right)$ which suggests that the genetic controls of the two traits are linked. The estimated mapping distance between the root and tuber resistance loci is $38 \pm 5$ centimorgans (6). Both phenotypic traits considered alone conform to a dominant monogenic model; 76 root resistant versus 77 root susceptible $\left(\chi^{2}=0.006\right.$, not significant), as would be expected (5), and 78 tuber resistant versus 75 tuber susceptible $\left(\chi^{2}=0.06\right.$, not significant). This is the first report of inheritance of the tuber resistance. Our preliminary analysis points to two genetic factors, expressed independently, linked on chromosome 11. A tuber resistance phenotype was expressed in the original $S$. bulbocastanum parent (SB22) (unpublished data) and probably is the source of the resistance in this backcross introgressant.

Summary. Two aspects of resistance to Columbia root-knot nematode have been described: resistance to root reproduction controlled by a single dominant gene located on chromosome 11 , with the previously reported symbol of $R_{M c l(b l b)}(5)$. In a single breeding line, PA99N82-4, an additional resistance was discerned in the failure of juveniles to penetrate tubers and reproduce, causing internal blemishing and external galling. Originally noted in tests to show the role of extraneous juveniles emanating from weed hosts to the breakdown of resistance, all breeding lines but this one were susceptible to weed-incited tuber infestation. Tuber infestation appears to have a broad spectrum of activity encompassing both races of $M$. chitwoodi (races 1 and 2), and two resistance-breaking pathotypes, CRKN-1 ${ }_{(\mathrm{Pl})}$ and $\mathrm{CKRN}-2_{(\mathrm{Pl})}$, which have similar host preferences to races 1 and 2, respectively, but which colonize the original source of resistance in $S$. bulbocastanum selection 22. Resistance to tuber infestation derived from PA99N82-4 appears to be controlled by a dominant monogene loosely linked to root resistance. The following symbol, $R_{\text {Mctuber(blb) }}$, is proposed to denote the genetic factor controlling resistance to tuber infection by races 1 and 2, pathotypes $\mathrm{CRKN}-2_{(\mathrm{P} 1)}$ and $\mathrm{CRKN}-1_{(\mathrm{P} 1)}$, and which, due to its linkage to $R_{M c l(b l b)}$, is inferred to be located on chromosome 11. Its taxonomic origin is $S$. bulbocastanum.

\section{ACKNOWLEDGMENTS}

E. Riga is supported by the College of Agricultural, Human, and Natural Resource Sciences Agricultural Research Center, PPNS no. 0542, Department of Plant Pathology and IAREC WSU-Prosser, project no. WNP00542, Washington State University, Pullman. We acknowledge grant support from the National Science Foundation and the Washington State Potato Commission.

\section{LITERATURE CITED}

1. Boydston, R. A., Mojtahedi, H., Brown, C. R., Anderson, T., and Riga, E. 2007. Hairy nightshade undermines resistance of potato breeding lines to Columbia root-knot nematode. Am. J. Potato Res. 84:245-252.

2. Brown, C. R., and Mojtahedi, H. 2005. Breeding for resistance to Meloidogyne species and Trichodorid-vectored virus. Pages. 267-292 in:
Genetic Improvement of Solanaceous crops: Volume 1: Potato. M. K. Razdan and A. K. Mattoo, eds. Science Publishers, Inc., Enfield, NH.

3. Brown, C. R., Mojtahedi, H., James S. J., Novy, R. G., and Love, S. L. 2006. Development and evaluation of potato breeding lines with introgressed resistance to Columbia root-knot nematode (Meloidogyne chitwoodi). Am. J. Potato Res. 83:1-8.

4. Brown, C. R., Mojtahedi, H., and Santo, G. S. 2003. Characteristics of resistance to Columbia root-knot nematode introgressed from several Mexican and North American wild potato species. Acta Hortic. 619:117125 .

5. Brown, C. R., Yang, C.-P., Mojtahedi, H., Santo, G. S., and Masuelli, R. 1996. RFLP analysis of resistance to Columbia root-knot nematode derived from Solanum bulbocastanum in a $\mathrm{BC}_{2}$ population. Theor. Appl. Genet. 92:572-576.

6. Griffiths, A. J. F. , Wessler, S. R., Lewontin, R. C., Gelvart, W. M., Suzuki, D. T., and Miller, J. H. 2004. An introduction to genetic analysis. W.H. Freeman, New York.

7. Hussey, R. S., and Barker, K. S. 1973. A comparison of methods of collecting inocula of Meloidogyne spp. including a new technique. Plant Dis. Rep. 57:1025-1028.

8. Jenkins, W. R. 1964. A rapid centrifugal-flotation technique for separating nematodes from soil. Plant Dis. Rep. 48:692.

9. Mojtahedi, H., Brown, C. R., Riga, E., and Zhang, L. H. 2007. A new pathotype of Meloidogyne chitwoodi Race 1 from Washington State. Plant Dis. 91:1051

10. Mojtahedi, H., Brown, C. R., and Santo, G. S. 1994. Root and tuber resistance in somatic hybrid of Solanum bulbocastanum and S. tuberosum to Meloidogyne chitwoodi. (Abstr.) J. Nematol. 26:560.

11. Mojtahedi, H., Pinkerton, J. N., Santo, G. S., and Peaden, R. N. 1989. Host status of alfalfa cultivars and germplasms to Meloidogyne chitwoodi race 2 and reactions of selected cultivars to M. hapla. Plant Dis. 73:391394.

12. Mojtahedi, H., Santo, G. S., Brown, C. R., Ferris, H., and Williamson, V. 1994. A new host race of Meloidogyne chitwoodi from California. Plant Dis 78:1010

13. Mojtahedi, H., Santo, G. S., and Wilson, J. H. 1988. Host tests to differentiate Meloidogyne chitwoodi, races 1 and 2, and M. hapla. J. Nematology 20:468-473.

14. Mojtahedi, H., Santo, G. S., Wilson, J. H., and Hang, A. N. 1993. Managing Meloidogyne chitwoodi on potato with rapeseed as green manure. Plant Dis. 77:42-46.

15. Mojtahedi, H., Van der Beek, J. G., Santo, G. S., and Brown, C. R. 1998. Reassessment of host race concept for Columbia root-knot nematode, Meloidogyne chitwoodi. (Abstr.) J. Nematol. 30:506-507.

16. Oostenbrink, M. 1966. Major characteristics of the relation between nematodes and plants. Meded. Landbouwhogesch. Wageningen 66:3-46.

17. Pinkerton, J. N., Mojtahedi, H., and Santo, G. S. 1987. Reproductive efficiency of Pacific Northwest populations of Meloidogyne chitwoodi on alfalfa. Plant Dis. 71:345-348.

18. Pinkerton, J. N., Santo, G. S., and Mojtahedi, H. 1991. Population dynamics of Meloidogyne chitwoodi on Russet Burbank potatoes in relation to degree-day accumulation. J. Nematol. 23:283-290

19. Roberts, P. A. 1995. Conceptual and practical aspects of variability on root-knot nematodes related to host plant resistance. Annu. Rev. Phytopathol. 33:199-221.

20. Santo, G. S., Mojtahedi, H., Martin, M. W., Hane, D. C., Brown, C. R., Pavek, J. J., and Wilson, J. H. 1994. Tuber resistance in a potato breeding clone that is a suitable host for Meloidogyne chitwoodi. (Abstr.) J. Nematol. 26:565.

21. Santo, G. S., O'Bannon, J. H., Finley, A. M., and Golden, A. M. 1980. Occurrence and host range of a new root-knot nematode (Meloidogyne chitwoodi) in the Pacific Northwest. Plant Dis. 64:951-952.

22. Santo, G. S., and Pinkerton, J. N. 1985. A second race of Meloidogyne chitwoodi discovered in Washington State. Plant Dis. 69:361.

23. Zhang, L.-H., Mojtahedi, H., Kuang, H., Baker, B., and Brown, C. R. 2007. The use of STS markers in the marker-assisted selection of resistance to Columbia root-knot nematode. Crop Sci. 47:2021-2026. 